\title{
The Design of a Near-Field Antenna with a Ferrite Sheet for UHF EPC Applications
}

\author{
Yi Seul Hwang ${ }^{*}$ Kyung Ho Lee · Yong Seung Jeon · Won Mo Sung
}

\begin{abstract}
In this letter, a small-loop antenna for a mobile UHF RFID device is proposed. To achieve size reduction, a ferrite sheet optimized for a 900 $\mathrm{MHz}$ band is applied. The overall dimensions of the antenna are $46 \mathrm{~mm} \times 35 \mathrm{~mm} \times 0.24 \mathrm{~mm}$, and it has a bandwidth of $45 \mathrm{MHz}$ with a return loss of less than $-6 \mathrm{~dB}$. The proposed antenna satisfies near and far field UHF EPC global frequency band communications (902-928 MHz).
\end{abstract}

Key Words: Antenna, Electronic Product Code (EPC), Ferrite Sheet, Internet of Things, Radio Frequency Identification (RFID).

\section{INTRODUCTION}

The Internet of things (IoT) refers to the interconnection of services and technology used by all people, goods, and data to collect, share, and create information via the Internet. It will be applied to not only information and communication technology (ICT), but also to industry in general. It is therefore expected to solve the social problems and inconveniences of daily life. For this reason, the government has attracted attention to IoT as a growth engine for the next generation [1].

The services and technology of the Io $\mathrm{T}$ are in contact on a daily basis. Radio frequency identification (RFID) technology is the most widely used IoT technology and is compatible with various smart phones and forms of payment. RFID is used to identify objects from a distance of a few meters using a stationary reader to communicate wirelessly with small battery-free transponders (tags) attached to objects. It also provides two important basic functions for IoT: the identification and communication of RFID. It can be used to determine the approximate location of objects, thereby providing the position of the reader [2, 3].

This paper proposes a small loop antenna for mobile UHF RFID devices. To reduce the antenna size, a ferrite sheet optimized for $900 \mathrm{MHz}$ band is applied. The performance of the antenna is investigated by comparing it to that of an antenna without a ferrite sheet.

\section{Antenna Configuration}

\section{Ferrite Sheet Characteristics}

Ferrite sheets show high permeability and high permittivity. These characteristics are highly desirable for the miniaturization of many different $\mathrm{RF} /$ microwave devises, including antennas. In particular, the characteristic of high permeability is effective for increasing recognition distance by strengthening the flux density of the magnetic field on near-field communication antennas. To find the range of effective permeability on the UHF band, we simulated the recognition distance corresponding to the permeability, as shown in Fig. 1. Fig. 1 shows an inductive coupling simulation result with both a manufactured antenna and a

Manuscript received July 30, 2014 ; Revised September 11, 2014 ; Accepted September 17, 2014. (ID No. 20140730-033J)

EMW Co. Ltd., Suwon, Korea.

*Corresponding Author: Yi Seul Hwang (e-mail: yshwang@emw.co.kr)

This is an Open-Access article distributed under the terms of the Creative Commons Attribution Non-Commercial License (http://creativecommons.org/licenses/ by-nc/3.0) which permits unrestricted non-commercial use, distribution, and reproduction in any medium, provided the original work is properly cited.

(c) Copyright The Korean Institute of Electromagnetic Engineering and Science. All Rights Reserved. 


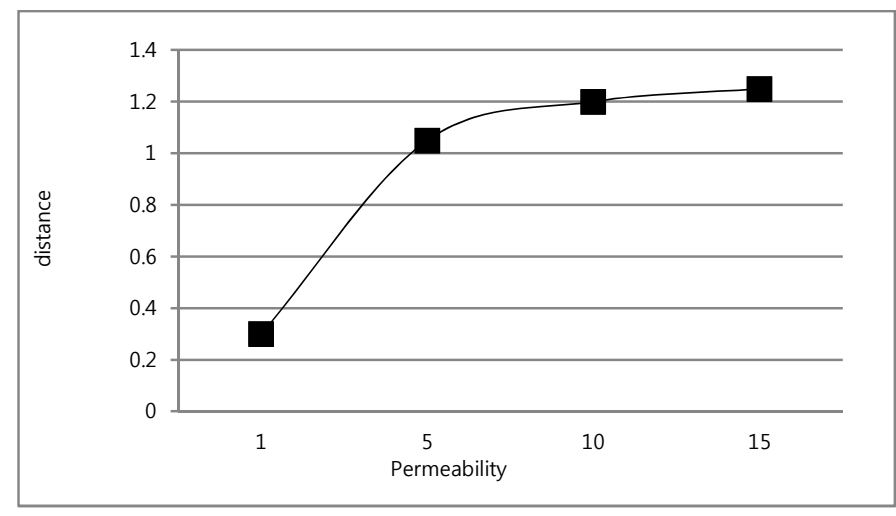

Fig. 1. Distance versus permeability.

standard antenna. Each of the antennas is made of magnetic permeability. In terms of permeability, the same frequency is represented while maintaining distance. With high permeability, distance characteristics appear further away. As the permeability becomes higher, the recognition distance becomes enlarged. However, if the permeability is greater than 8 , it can be confirmed that the increased rate of recognition distance is reduced. Thus, the optimal range of permeability is from 8 to 10 . Conventional ferrite sheets on the HF band are made of the spinel type cobalt ferrite. In this paper, due to the characteristics of low magnetic loss and higher permeability on the UHF band, hexagonal barium ferrite (Ba-ferrite) was used, and the ferrite sheet was annealed at $800^{\circ} \mathrm{C}-900^{\circ} \mathrm{C}$. The constitutive parameters of

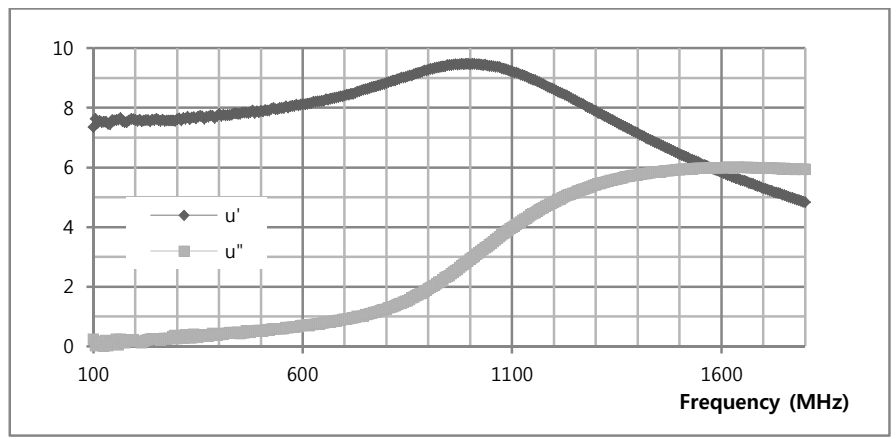

(a)

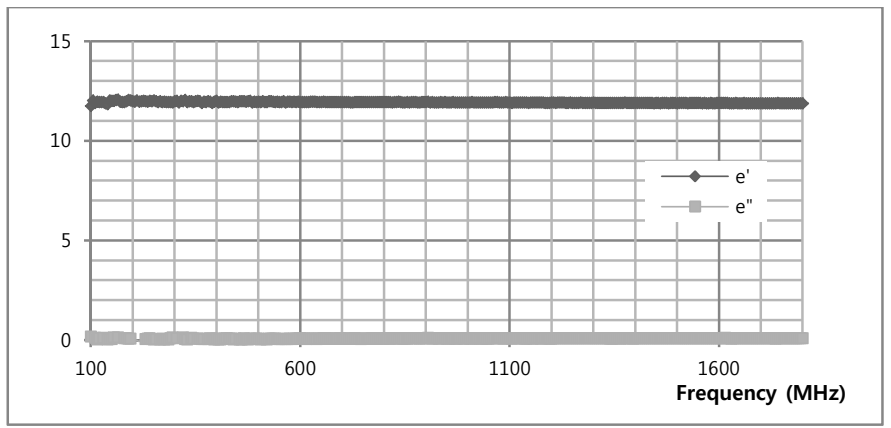

(b)

Fig. 2. Constitutive parameters of ferrite sheet. (a) Complex relative permeability and (b) complex relative permittivity. ferrite sheet are shown in Fig. 2. It has a complex relative permeability of $9.29+j 1.93$ and a permittivity of $11.92+j 0.08$, respectively, at $900 \mathrm{MHz}$.

\section{Antenna Configuration}

Fig. 3 shows the configuration of the proposed antenna. The proposed antenna consists of a loop and a ferrite sheet. The loop antenna is fabricated on a flexible printed circuit board (PCB) with a thickness of $0.08 \mathrm{~mm}$. The performance of a loop antenna is designed by considering that the antenna is attached on a ferrite sheet with a thickness of $0.16 \mathrm{~mm}$. The dimension is 46 $\mathrm{mm} \times 35 \mathrm{~mm} \times 0.24 \mathrm{~mm}$. The proposed antenna is optimized using the CST Microwave Studio (CST MSW; Computer Simulation Technology AG., Darmstadt, Germany)—3D EM simulator. The optimal design parameters for the proposed antenna are shown in Fig. 3.

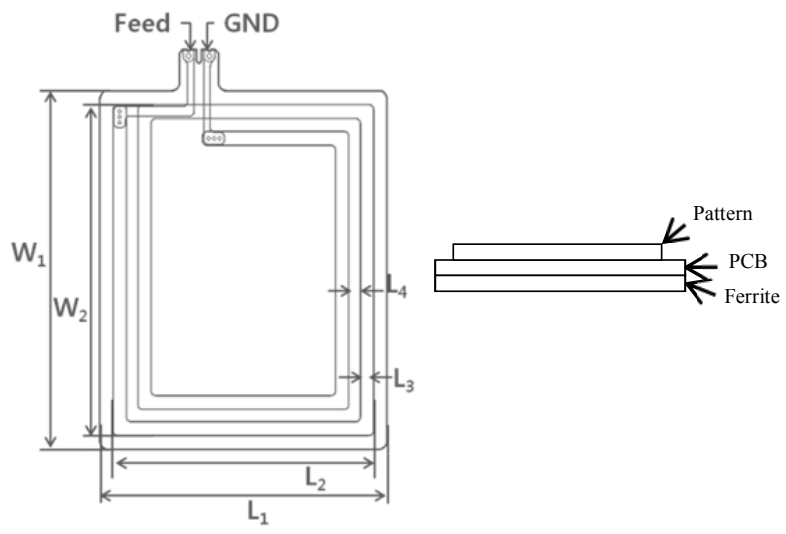

\begin{tabular}{|c|c|c|c|}
\hline$W_{1}$ & $46 \mathrm{~mm}$ & $W_{2}$ & $40 \mathrm{~mm}$ \\
\hline$L_{1}$ & $35 \mathrm{~mm}$ & $L_{2}$ & $29 \mathrm{~mm}$ \\
\hline $\begin{array}{c}L_{3} \text { (Pattern } \\
\text { width) }\end{array}$ & $1.0 \mathrm{~mm}$ & $\begin{array}{c}L_{4}(\text { Pattern } \\
\text { gap) }\end{array}$ & $0.8 \mathrm{~mm}$ \\
\hline
\end{tabular}

(a)

\begin{tabular}{cc}
\hline Pattern & Copper \\
PCB & FR4 \\
Ferrite & $\varepsilon: 10, \quad \mu: 10$ \\
\hline
\end{tabular}

(b)

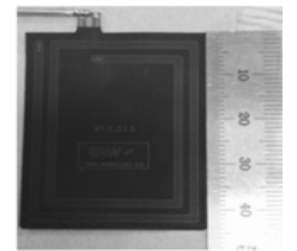

(c)

Fig. 3. Optimized design parameters of the proposed antenna. (a) Antenna dimensions, (b) layers of the antenna, and (c) photography of the fabricated antenna. 


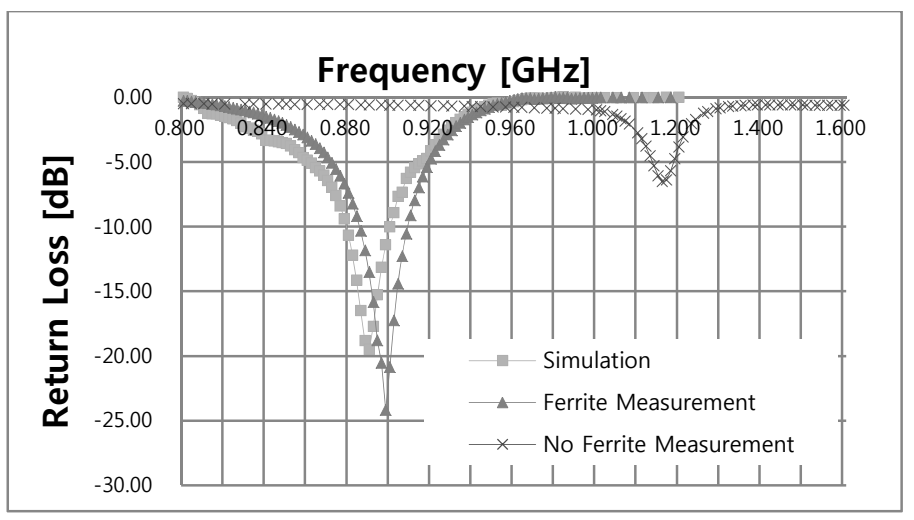

Fig. 4. Return loss characteristics.

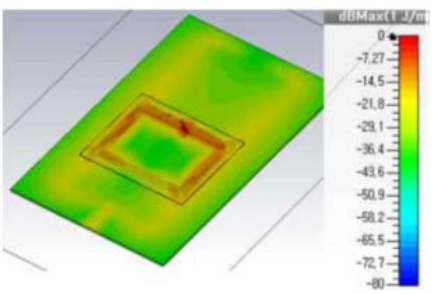

(a)

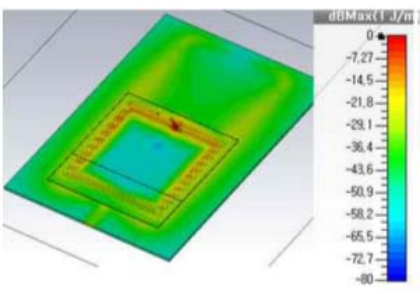

(b)
Fig. 5 Simulated magnetic energy distributions. (a) Optimized antenna attached on ferrite sheet and (b) opptimized antenna without ferrite sheet.

\begin{tabular}{|c|c|c|c|c|c|c|}
\hline \multirow{2}{*}{$\begin{array}{l}\text { Freq. } \\
(\mathrm{MHz})\end{array}$} & \multicolumn{2}{|c|}{ Theta-Pol (H) } & \multicolumn{2}{|c|}{ Phi-Pol (V) } & \multicolumn{2}{|c|}{ PwrSum } \\
\hline & $\begin{array}{l}\text { Avg. } \\
(\mathrm{dBi})\end{array}$ & $\begin{array}{l}\text { Peak } \\
(\mathrm{dBi})\end{array}$ & $\begin{array}{l}\text { Avg. } \\
(\mathrm{dBi})\end{array}$ & $\begin{array}{l}\text { Peak } \\
(\mathrm{dBi})\end{array}$ & $\begin{array}{l}\text { Avg. } \\
(\mathrm{dBi})\end{array}$ & $\begin{array}{l}\text { Peak } \\
(\mathrm{dBi})\end{array}$ \\
\hline 840 & -5.37 & -2.25 & -15.96 & -9.45 & -5.01 & -2.18 \\
\hline 890 & -5.18 & -1.81 & -15.88 & -9.77 & -4.82 & -1.79 \\
\hline 940 & -6.92 & -3.91 & -19.37 & -14.09 & -6.68 & -3.85 \\
\hline
\end{tabular}

(a)

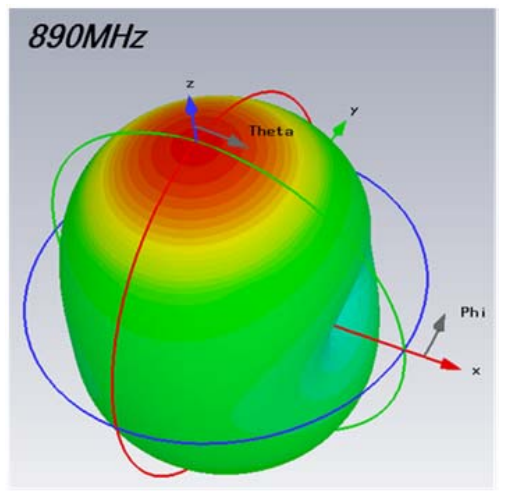

(b)

Fig. 6 Antenna gain and radiation pattern of ferrite sheet optimized antenna. (a) Antenna gain and (b) antenna radiation pattern.

\section{Results and Discussion}

Fig. 4 shows the simulated and measured return loss characteristics of the proposed antenna. The measured result agreed with the simulated one. From the measurement, the $6 \mathrm{~dB}$ return loss bandwidth was $45 \mathrm{MHz}$ (5\%) ranging from 880 to $925 \mathrm{MHz}$, which is wide enough to cover the entire EPC UHF band $(902-928 \mathrm{MHz})$.

To evaluate the performances of the proposed antenna, a rectangular loop without a ferrite sheet is optimized on the same resonance frequency. The size of the proposed antenna is about $70 \%$ of that of the compared antenna. The permeability widens the antenna bandwidth. The permittivity reduces the antenna size but narrows the antenna bandwidth. Thus, both permeability and permittivity reduce antenna size without narrowing the bandwidth. Fig. 5 depicts the simulated magnetic energy distributions on each rectangular loop antenna at $900 \mathrm{MHz}$. One can clearly see that the proposed antenna has enhanced magnetic energy density in spite of its small size. Fig. 6(a) and (b) shows the measured antenna gain. We can see that at 900 $\mathrm{MHz}(840-940 \mathrm{MHz})$, the antenna has an average gain of about $-5 \mathrm{dBi}$.

\section{Conclusion}

A small loop antenna for mobile UHF RFID devices is proposed. By applying a ferrite sheet optimized for a $900 \mathrm{MHz}$ band, the size of the antenna is reduced to about $70 \%$ of that of a conventional rectangular loop. In spite of its small size, it has a bandwidth of $45 \mathrm{MHz}$ for a return loss less than $-6 \mathrm{~dB}$ and yields superior magnetic energy density. The proposed antenna is sufficient to cover both near and far field UHF EPC global frequency band communications (902-928 MHz).

\section{REFERENCES}

[1] J. Ko, S. G. Hong, B. B. Lee, and N. S. Kim, "Trends of converging smart device with IoT technology," Electronics and Telecommunications Trends, vol. 28, no. 4, pp. 79-85, 2013.

[2] F. Mattern and C. Floerkemeier, "Vom internet der computer zum internet der dinge," Informatik-Spektrum, vol. 33, no. 2, pp. 107-121, 2010.

[3] K. Finkenzeller, RFID Handbook: Fundamentals and Applications in Contactless Smart Cards and Identification. Hoboken, NJ: John Wiley \& Sons, 2003. 